\title{
Protective effects of postconditioning in transvaginally created pneumoperitoneum
}

\author{
KOBA SHANAVA $^{1,2}$, SZANISZLO JAVOR ${ }^{2}$, VAKHTANG KERKADZE ${ }^{1,3}$, \\ IVANE ABIATARI $^{1}$ and GYÖRGY WEBER ${ }^{2,4}$
}

\author{
${ }^{1}$ Institute of Medical Research, Ilia State University, Tbilisi 0162, Georgia; ${ }^{2}$ Department of Surgical Research and \\ Techniques, Medical Faculty, University of Pecs, H-7624 Pécs, Hungary; ${ }^{3}$ Faculty of Medicine, Georgian National \\ University SEU, Tbilisi 0166, Georgia; ${ }^{4}$ Department of Surgical Research and Techniques, \\ Semmelweis University, H-1085 Budapest, Hungary
}

Received May 23, 2019; Accepted November 25, 2019

DOI: $10.3892 /$ etm.2020.8616

\begin{abstract}
There are reports of ischemic complications in clinical practice after laparoscopy using pneumoperitoneum. Conditioning has a beneficial effect for various ischemic diseases. This experimental study was designed to evaluate the effects of postconditioning in transvaginally created pneumoperitoneum. Sixty adult female rats, weighing $300 \pm 50 \mathrm{~g}$ were divided into four equal groups. Pneumoperitoneum was created by $\mathrm{CO}_{2}$ insufflation under a pressure of $10 \mathrm{mmHg}$. Rats in the first group (sham) were subjected to only sham-operation or gas insufflation. The second group (TV/PP) was subjected to pneumoperitoneum for $60 \mathrm{~min}$ followed by $30 \mathrm{~min}$ of desufflation. The third group (post-5) was subjected to pneumoperitoneum for $60 \mathrm{~min}$ followed by $5 \mathrm{~min}$ of desufflation, $5 \mathrm{~min}$ of insufflation and again followed by $30 \mathrm{~min}$ of desufflation. The fourth group (post-2.5) was subjected to pneumoperitoneum for $60 \mathrm{~min}$ followed by $2.5 \mathrm{~min}$ of desufflation and $2.5 \mathrm{~min}$ of insufflation-repeated in two cycles- and then followed by $30 \mathrm{~min}$ of desufflation. The rats were sacrificed, and blood was collected after $30 \mathrm{~min}, 2$ and $6 \mathrm{~h}$ from the last desufflation. Levels of oxidative stress markers, malondialdehyde (MDA), superoxide dismutase (SOD), reduced glutathione (GSH), sulfhydryl groups (SH) and inflammatory cytokine TNF- $\alpha$, were analyzed. Levels of MDA in the post- 5 group were significantly reduced compared to the TV/PP and post- 2.5 groups. The level of GSH in TV/PP animals was markedly reduced compared to the Sham, Post-5 and Post- 2.5 groups. In addition, levels of SH were increased in the Post-5 group in comparison to the Sham, TV/PP and Post-2.5 groups. No difference in the activity of SOD between the groups was found, and the concentration of
\end{abstract}

Correspondence to: Professor Ivane Abiatari, Institute of Medical Research, Ilia State University, 3/5 Cholokashvili Avenue, Tbilisi 0162, Georgia

E-mail: ivane.abiatari@iliauni.edu.ge

Key words: pneumoperitoneum, transvaginal, postconditioning, oxidative stress
TNF- $\alpha$ in TV/PP animals was significantly higher than that in the Sham and postconditioning groups. Overall, the results of the present study indicate that postconditioning can reduce pneumoperitoneum-induced oxidative injury.

\section{Introduction}

Laparoscopy was first described in the beginning of the 20th century as a valuable adjunct to the diagnosis of diseases of the abdominal cavity. At present, laparoscopic surgery is reputed as one of the most effective diagnostic and therapeutic tools in general surgery. The benefits of laparoscopy versus open surgery include several advantages such as less post-operative pain, shorter recovery time and less post-operative scarring (1). However, it must also be pointed out, that there are a number of complications, which may occur after laparoscopy. It is known that pneumoperitoneum, which is created for adequate visualization of the organs during laparoscopy, increases intra-abdominal pressure. The latter reduces organ perfusion and this is associated with splanchnic ischemia/reperfusion (I/R) injury and oxidative stress (2-6). The level of injury is dependent on the magnitude of the pressure and application time (7). It has been confirmed that increasing intra-abdominal pressure from 10 to $15 \mathrm{mmHg}$, decreases blood flow in the stomach by $40 \%$, the duodenum by $11 \%$, the jejunum by $32 \%$, the colon by $44 \%$, the liver by $39 \%$ and the parietal peritoneum by $60 \%$ (2).

Numerous reports are available in the literature concerning the formation of excessive amounts of oxygen-derived free radicals in ischemic reperfused tissues. Many vital organs including the brain, lung, heart, liver, kidney, intestine, gastric mucosa and stomach can be subjected to I/R injury; and it seems that oxygen free radicals play a major role in the pathogenesis of the cellular injury $(8,9)$.

Several strategies for the prevention of pneumoperitoneum-induced oxidative stress, such as preconditioning and postconditioning, Trendelenburg positioning and insufflation with helium, have been introduced in recent years, showing promising results $(5,7,10-12)$. Postconditioning, which comprises short ischemia periods applied at the time of reperfusion was first described in a canine model (13) and 
demonstrated protective effect against reperfusion injury. Despite the positive scientific reports regarding the effects of postconditioning, there is still limited understanding of the application and different regimens. In addition, prevention of the negative effects of pneumoperitoneum remains a problematic issue in laparoscopic surgery. Recently authors reported the effect of a 10-min ischemia postconditioning regimen (with 5 min of each-desufflation and insufflation), after pneumoperitoneum (7). The effect of postconditioning was evaluated by blood level analysis of oxidative stress markers and assessment of tissue morphology in animal models, which were initially established by our group (14). In the present study, we used a similar animal model and comparatively assessed two 10 -min postconditioning regimens: a) Desufflation/insufflation for $5 \mathrm{~min}$ each; b) desufflation/insufflation for $2.5 \mathrm{~min}$ each-repeated twice ( 2 cycles). Furthermore, we analyzed levels of blood oxidative stress markers at three different time points after pneumoperitoneum (30 min, 2 and $6 \mathrm{~h}$ ).

The aim of the present experimental study was to characterize the effects of two different postconditioning regimens in transvaginally created pneumoperitoneum in a rat animal model.

\section{Materials and methods}

\section{Animals and study design}

Animals. Sixty adult female Wistar rats each weighing $300 \pm 50 \mathrm{~g}$ were acquired from the Ilia State University animal house and housed in cages (under normal atmosphere, standard room temperature and 12-h light/dark cycle conditions) where standard rodent chow and water were available. The rats went without food for $12 \mathrm{~h}$ before any procedures. Animals were anesthetized by intraperitoneal (i.p.) injection of ketamine $(37.5 \mathrm{mg} / \mathrm{kg})$ and seduxen $(3.75 \mathrm{mg} / \mathrm{kg})$. All animal experiments were in compliance with the ARRIVE guidelines and were carried out in accordance with the U.K. Animals (Scientific Procedures) Act, 1986 and associated guidelines. These studies were approved by the Local Institutional Committee on Animal Research of Pecs University, Hungary.

Study design. The animals were divided into four equal groups-each consisting of 15 rats, which also were divided into three subgroups according to the time of blood taken $(n=5)$ (explained below). In all animals other than the sham group, the pneumoperitoneum was created by $\mathrm{CO}_{2}$ insufflation under a pressure of $10 \mathrm{mmHg}$; because of this, the Veress needle was placed into the abdominal cavity from the vaginal orifice as previously described (14), which was connected to an insufflator (Karl Storz GmbH \& Co. KG). In two cases bleeding was observed from the outer part of the vaginal orifice after the placement of the Veress needle. No other complications were noted during the surgical procedures.

Study groups. Group 1: Sham-operation group. A Veress needle was placed into the vaginal orifice without any other surgical procedure or gas insufflation. Group 2: Transvaginal pneumoperitoneum (TV/PP) group was subjected to pneumoperitoneum for $60 \mathrm{~min}$ followed by $30 \mathrm{~min}$ of desufflation. Group 3: Postconditioning with 5 min. (Post-5) was subjected to pneumoperitoneum for $60 \mathrm{~min}$, plus 5 min of desufflation and $5 \mathrm{~min}$ of insufflation followed by $30 \mathrm{~min}$ of desufflation. Group 4: Post-conditioning with cycle (Post-2.5) was subjected to pneumoperitoneum for $60 \mathrm{~min}$ plus $2.5 \mathrm{~min}$ of desufflation and $2.5 \mathrm{~min}$ of insufflation repeated in two cycles and followed by $30 \mathrm{~min}$ of desufflation.

Animals were sacrificed after $30 \mathrm{~min}, 2$ and $6 \mathrm{~h}$ from the last desufflation. The blood samples were collected in each group at the aforementioned times from all animals by cardiac puncture. Oxidative stress markers such as malondialdehyde (MDA), superoxide dismutase (SOD), reduced glutathione (GSH) and sulfhydryl group (SH) levels as well as inflammatory cytokine TNF- $\alpha$ concentrations were measured in all samples.

Biochemical tests. For detection of MDA concentration, $4.5 \mathrm{ml}$ thiobarbituric acid (TBA) and trichloroacetic acid (TCA) mixture was added to $0.5 \mathrm{ml}$ diluted blood sample or its plasma. The sample was incubated at $100^{\circ} \mathrm{C}$ (in boiling water) for $20 \mathrm{~min}$ and cooled in icy water. Afterwards, the sample was centrifuged for $15 \mathrm{~min}$ at $1,400 \mathrm{x} \mathrm{g}$, and measurement with a spectrophotometer was performed at $532 \mathrm{~nm}$. The MDA concentration was calculated in $\mathrm{nmol} / \mathrm{ml}$ (15).

For detection of reduced GSH and SH concentrations, $1 \mathrm{ml}$ quintuple diluted blood sample and $4 \mathrm{ml}$ trichloroacetic acid (TCA) mixture were used for determination. The mixture was centrifuged for $15 \mathrm{~min}$ at $18 \mathrm{xg}$. Two milliliters of the supernatant was added to $4 \mathrm{ml}$ Tris buffer (0.4 M,pH 8.7), and $100 \mu \mathrm{l}$ of 5,5'-dithiobis-(2-nitrobenzoic acid) (DTNB) was added to the mixture immediately before the measurement was taken. Measurement with a spectrophotometer was made at $412 \mathrm{~nm}$ with concentrations calculated in $\mathrm{nmol} / \mathrm{ml}$ (16).

For detection of SOD activity, $1 \mathrm{ml}$ blood mixed with EDTA was used. Nine milliliters of Hartman's solution was added to the blood sample and centrifuged for $5 \mathrm{~min}$ at $380 \mathrm{x}$ g. This washing procedure was repeated after the discarding of the supernatant. One milliliter of a chloroform and ethanol (2:1) mixture was added to $1 \mathrm{ml}$ of hemolyzed erythrocytes and centrifuged for $4 \mathrm{~min}$ at $12,000 \mathrm{x} \mathrm{g}$. The supernatant was then separated, and adrenalin (16.488 $\mathrm{mg}$ adrenalin diluted in $10 \mathrm{ml}$ $0.1 \mathrm{~N}$ hydrochloric acid) was added to the supernatant with concentrations measured at $480 \mathrm{~nm}$ by a spectrophotometer. Concentrations were calculated in U/ml (17).

For the TNF- $\alpha$ concentration, detection was carried out using an ELISA kit (Quantikine ${ }^{\circledR}$ Rat TNF- $\alpha /$ TNFSF1A Immunoassay, R\&D Systems; cat. no. RTA00) according to the manufacturer's instructions. Concentration was calculated in $\mathrm{pg} / \mathrm{ml}$.

Statistical analysis. All data are presented as mean values \pm standard error of mean (SEM), which were compared within the various groups using one-way analysis of variance followed by Bonferroni post hoc tests and the non-parametric Mann-Whitney $\mathrm{U}$ test as appropriate. $\mathrm{P}<0.05$ was considered to indicate a statistically significant difference.

\section{Results}

After successful modeling of pneumoperitoneum in the experimental animals (all rats survived until the end of the 
experiment), we measured blood oxidative stress markers upon different postconditioning settings.

Analysis of MDA levels after 30 min showed significant upregulation in all experimental groups compared to sham group (Fig. S1A). At 2 and $6 \mathrm{~h}$, the levels of MDA in the post-5 group were significantly decreased $(72.11 \pm 2.85 \mathrm{nmol} / \mathrm{ml}$ after $2 \mathrm{~h}$ and $74.43 \pm 1.24 \mathrm{nmol} / \mathrm{ml}$ after $6 \mathrm{~h}$ ) compared with the TV/PP group at both 2 and $6 \mathrm{~h}$, and post- 2.5 group at $6 \mathrm{~h}$ (Fig. 1A and $\mathrm{B} ; \mathrm{P}<0.05)$. In the TV/PP group, the level of MDA was significantly increased compared to the Sham and Post-5 groups (Fig. 1A and $\mathrm{B} ; \mathrm{P}<0.05$ ), and maximum level of $89.58 \pm 7.87 \mathrm{nmol} / \mathrm{ml}$ was shown after $6 \mathrm{~h}$ (Fig. $1 \mathrm{C} ; \mathrm{P}<0.05$ ).

Next, we sought to analyze levels of GSH in the studied animals. Our experiment demonstrated that GSH blood levels were decreased in the TV/PP group $(847.25 \pm 86.17 \mathrm{nmol} / \mathrm{ml})$ compared to the Sham $(1,075.86 \pm 48.92 \mathrm{nmol} / \mathrm{ml})$, Post-5 $(1,051.13 \pm 92.14 \mathrm{nmol} / \mathrm{ml})$ and Post-2.5 $(1,008.32 \pm 94.67 \mathrm{nmol} / \mathrm{ml})$ groups after $30 \mathrm{~min}$ (Fig. 2A; P<0.05 for TV/PP vs. Sham or Post-5). After 2 and $6 \mathrm{~h}$ there were no marked differences in GSH level between the groups (Fig. S1B and C). Additionally, analysis of the levels of SH demonstrated that levels of blood SH were markedly increased in Post -5 groups $(47.30 \pm 4.81 \mathrm{nmol} / \mathrm{ml}$ after $30 \mathrm{~min}$ and $54.22 \pm 5.33 \mathrm{nmol} / \mathrm{ml}$ after $2 \mathrm{~h}$ ) in comparison to the Sham, TV/PP and Post-2.5 groups (Fig. 2B-D). Animals in the Post-2.5 group demonstrated significant reduction of blood SH levels after $30 \mathrm{~min}(36.75 \pm 6.5), 2 \mathrm{~h}(38.21 \pm 2.7)$ and $6 \mathrm{~h}(44.52 \pm 4.1)$ compared to the TV/PP and Post-5 groups (Fig. 2B-D; P<0.05).

We also analyzed inflammatory cytokine TNF- $\alpha$ concentrations in the blood of the experimental animals. The postconditioning groups (Post-5/Post-2.5) displayed significantly reduced level of TNF- $\alpha$ (13.11 44.49 and $17.08 \pm 2.15 \mathrm{pg} / \mathrm{ml}$, respectively) compared to the TV/PP animals (29.89 $\pm 1.78 \mathrm{pg} / \mathrm{ml}$ ) after pneumoperitoneum (Fig. 3A; $\mathrm{P}<0.05)$. Remarkably, no differences between the groups regarding SOD activity were found at any time point (Figs. 3B and $\mathrm{S} 2 \mathrm{~A}$ and $\mathrm{B}$ ).

\section{Discussion}

It is known that during pneumoperitoneum there is a cascade of chemical release occurring after peritoneal tissue stress, insult and damage (18). The proceeding hypoperfusion caused by insufflation of the abdominal cavity (under pressure of $10 \mathrm{mmHg}$ ) may induce ischemia/reperfusion (I/R) injury.

Authors have reported experimental results demonstrating diverse stress conditions of different gases and high/low-pressure settings for the establishment of pneumoperitoneum $(19,20)$. The conditioning of pneumoperitoneum has been suggested to be valuable and is an $\mathrm{I} / \mathrm{R}$ protective tool (10). There are few reports concerning the use of the conditioning model to prevent the negative effects related to the pneumoperitoneum associated with respiratory, homeostatic and physiologic consequences $(5,7,11,12,21)$. It was concluded that conditioning is more effective than pre-ischemic administration of erythropoietin in reducing the negative effects of oxidative injury (22).

Ischemic postconditioning is a new, simple manipulation that can protect organs from I/R injury. It has been shown
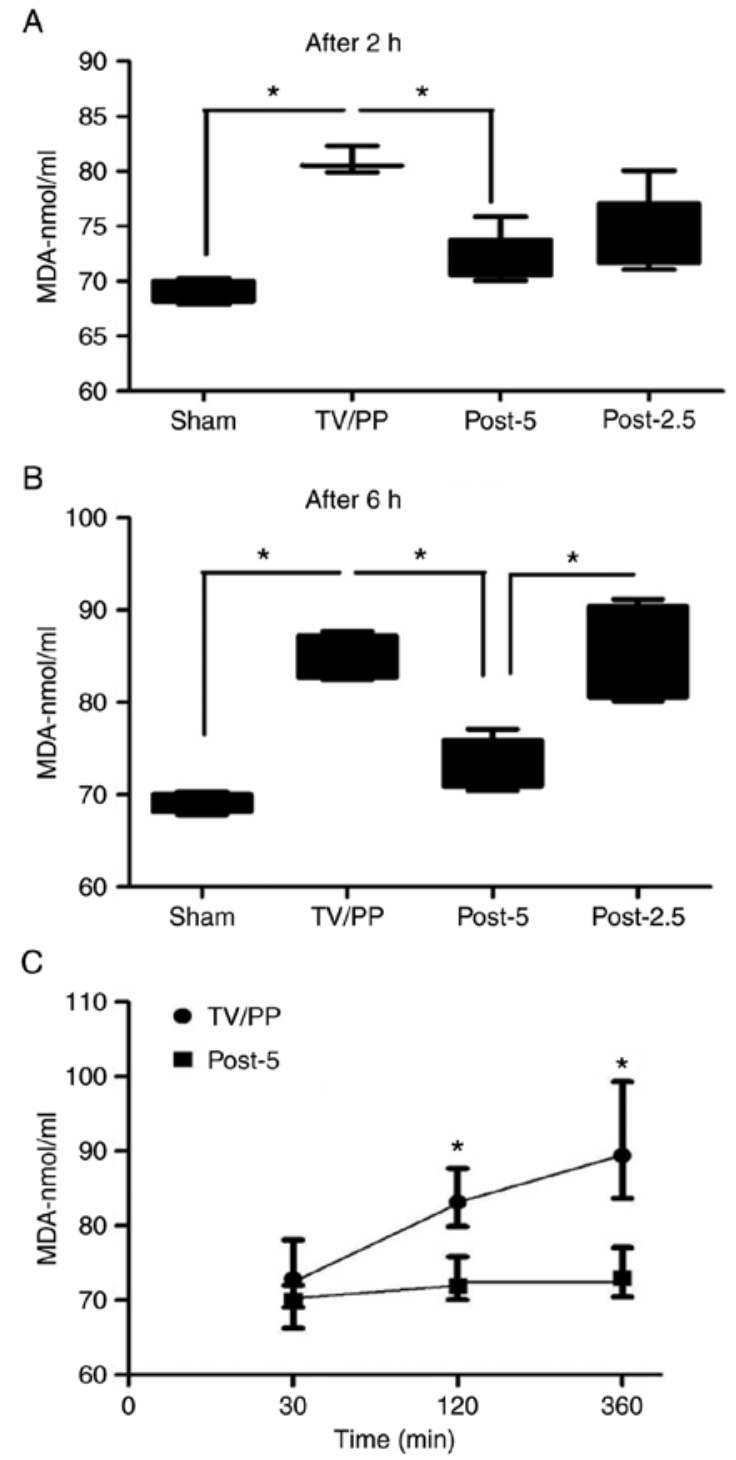

Figure 1. Blood levels of MDA in the Sham, TV/PP, Post-5 and Post-2.5 groups after (A) 2 and (B) $6 \mathrm{~h}$ of pneumoperitoneum. (C) Dynamics of the blood MDA levels in the TV/PP and Post-5 animal groups. ${ }^{*} \mathrm{P}<0.05$. MDA, malondialdehyde; TV/PP, transvaginal pneumoperitoneum.

that much of the post-ischemic injury occurs during the early moments of reperfusion, and that manipulation of this early reperfusion phase reduces I/R injury (10). We may assume that repetitive blood flow interruptions of tissues and organs applied immediately after a period of ischemia make tissues more resistant/tolerant to subsequent ischemic injury.

In our experiments, we created pneumoperitoneum conditions using a transvaginal approach due to the advantages of NOTES (Natural Orifice Transluminal Endoscopic Surgery) procedures, which are associated with less traumatic stress $(14,23)$. Simultaneously, however, we wanted to achieve substantial oxidative stress, and therefore stressful levels of pneumoperitoneum pressure were applied $(10 \mathrm{mmHg})(24,25)$. Indeed, this approach resulted in extensive elevation of oxidative stress parameters (TV/PP animal group). In order to effectively reduce negative signs of pneumoperitoneum, we decisively chose to use two different regimens of postconditioning in this transvaginally created pneumoperitoneum model. 

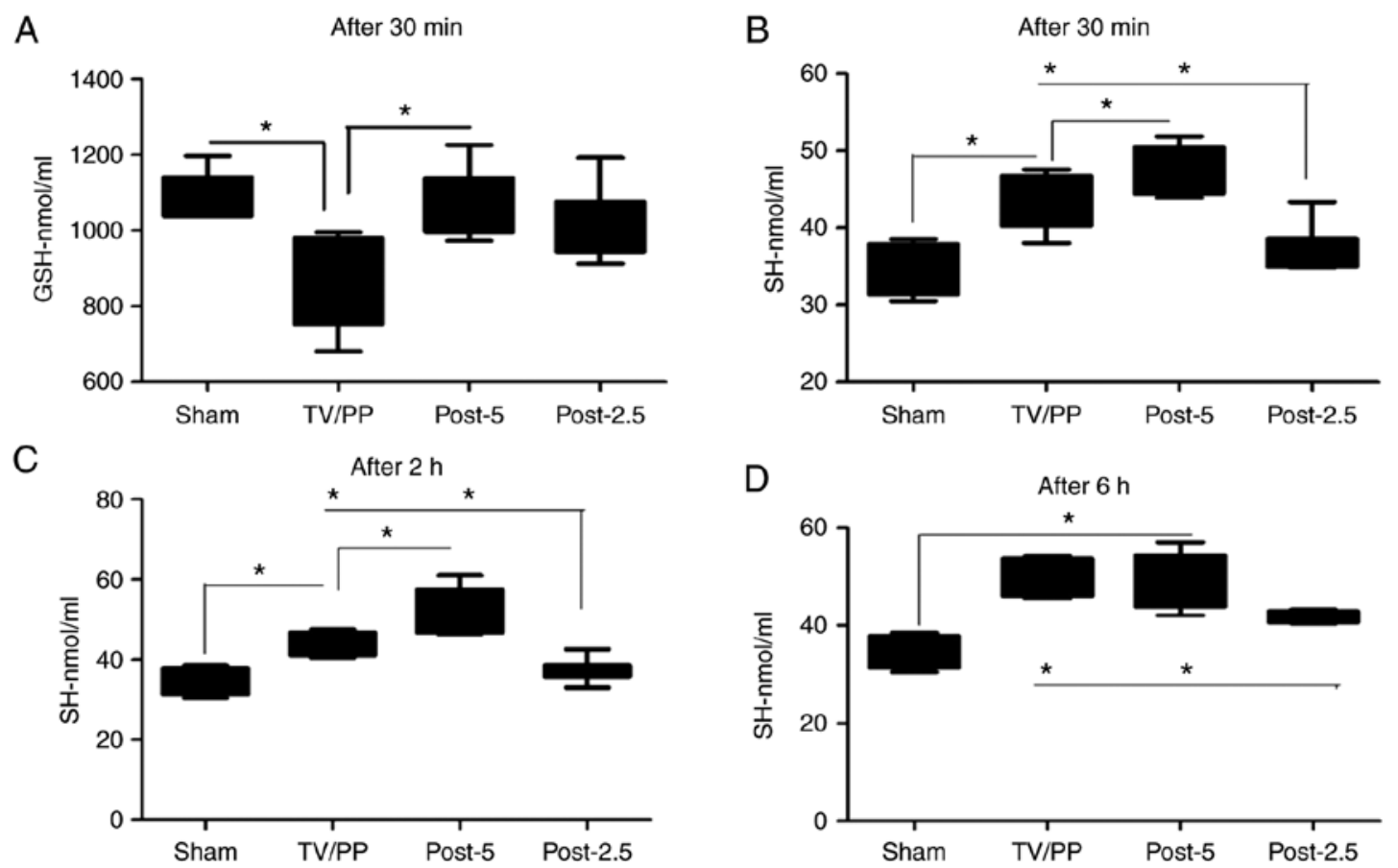

Figure 2. (A) Blood levels of GSH in the Sham, TV/PP, Post-5 and Post-2.5 groups after 30 min of pneumoperitoneum. (B-D) Levels of SH groups after $30 \mathrm{~min}(\mathrm{~B}), 2 \mathrm{~h}$ (C) and $6 \mathrm{~h}$ (D) of pneumoperitoneum. ${ }^{*} \mathrm{P}<0.05$. GSH, reduced glutathione; SH, sulfhydryl groups; TV/PP, transvaginal pneumoperitoneum.
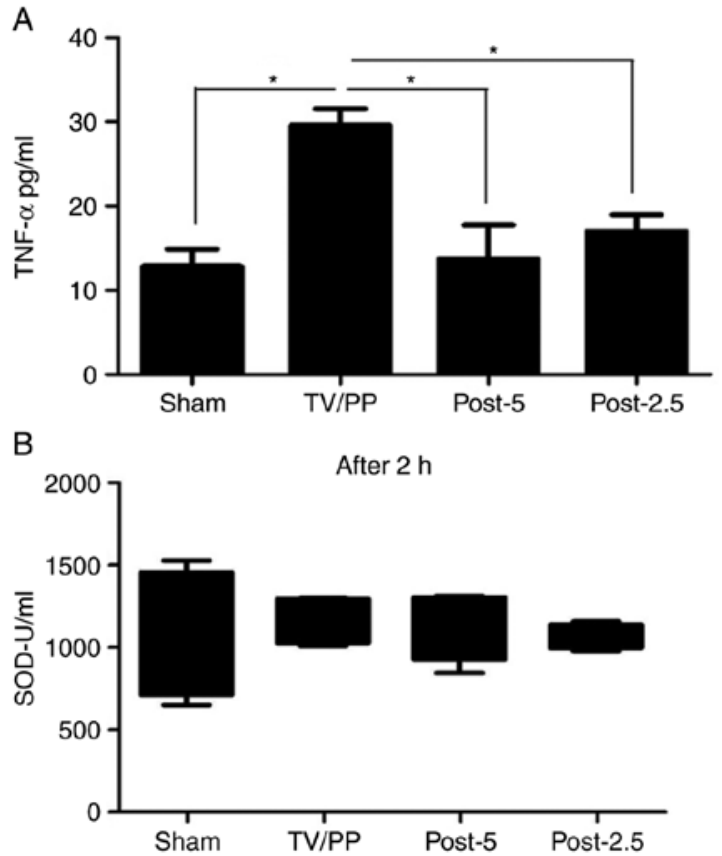

Figure 3. (A) Levels of TNF- $\alpha$ in the Sham, TV/PP, Post-5 and Post-2.5 groups after pneumoperitoneum. (B) Activity of superoxide dismutase (SOD) after $2 \mathrm{~h}$ of pneumoperitoneum. ${ }^{*} \mathrm{P}<0.05$. TNF, tumor necrosis factor; TV/PP, transvaginal pneumoperitoneum.

Recently, the effects of a one cycle 5-min ischemic postconditioning has been reported in an animal model, which included 5 min of desufflation and 5 min of insufflation after pneumoperitoneum (7). In the present study, a similar animal model was used and we performed comparative analysis of the above mentioned regimen (Post-5) with two shorter cycled 2.5-min desufflation/insufflation regimen (Post-2.5). Duration of total postconditioning time was the same in both groups (10 min).

To ascertain the extent of oxidative stress, levels of several markers, malondialdehyde (MDA), superoxide dismutase (SOD), reduced glutathione (GSH) and sulfhydryl group (SH) levels, as well as inflammatory cytokine TNF- $\alpha$ were determined. Free radicals have been seen to generate the lipid peroxidation process in organisms. MDA is one of the final products of lipid peroxidation in the cells, and an increase in free radicals causes overproduction of MDA (26). It is also known that GSH is a major endogenous antioxidant produced by cells, and that it participates directly in the neutralization of free radicals and reactive oxygen compounds. Reactive oxygen species overproduced as a result of oxidative stress are potent oxidizing and reducing agents that can directly damage cellular membranes by lipid peroxidation (8). SH is considered a major plasma antioxidant in vivo; and most of the SH-groups are present over albumin and are major reducing groups present in body fluids (27). Cytokines, such as TNF- $\alpha$, play a key role in mediating the host inflammatory response. TNF- $\alpha$ is considered to be an initial mediator of the cytokine cascade and appears to be the first cytokine into the blood stream. The release of TNF- $\alpha$ is inhibited following hypoxia and re-oxygenation periods (28).

As expected, pneumoperitoneum caused upregulation of blood MDA and TNF- $\alpha$ levels. Introduction of the postconditioning method was found to significantly reduce lipid peroxidation process and cytokine release in the body of experimental animals, as well as increased levels of antioxidant factors such as GSH and SH. Notably, based on blood MDA level results, we can assume, that Post-5 regimen of postconditioning can more effectively reduce lipid peroxidation compared to the Post-2.5 regimen. Moreover, 
based on analysis of the $\mathrm{SH}$ results we can suggest that the Post-2.5 postconditioning setup markedly reduced release of antioxidant factors. Assessment of GSH, TNF- $\alpha$ and SOD showed more or less similar effect among these postconditioning groups. Based on the results it can be suggested that both a single cycle postconditioning regimen (Post-5) as well as the cycled postconditioning (Post-2.5) method can reduce oxidative stress and subsequently may decrease pneumoperitoneum-caused complications. However, according to our experiments it is also suggested that the single cycle postconditioning regimen (Post-5) can be more effective in this regard. Further basic and clinical investigations are necessary to better characterize the postconditioning regimens and their effects although any of these approaches may already provide important clinical implications.

To conclude, pneumoperitoneum used during laparoscopic surgery induces elevation of oxidative stress markers. Postconditioning can normalize levels of oxidative stress markers after pneumoperitoneum. Furthermore, the method of postconditioning without cycles seems to be rather effective compared with postconditioning with cycles.

\section{Acknowledgements}

Not applicable.

\section{Funding}

No funding was received.

\section{Availability of data and materials}

All data generated or analyzed during the present study are included in this published article.

\section{Authors' contributions}

KS, SJ and VK designed and performed the animal studies. $\mathrm{KS}$ and SJ performed and analyzed the biochemical experiments. GW, SJ and IA supervised and aided the experimental research, and participated in the data collection and analysis. KS, SJ, IA and GW drafted the manuscript. All authors read and approved the manuscript and agree to be accountable for all aspects of the research in ensuring that the accuracy or integrity of any part of the work are appropriately investigated and resolved.

\section{Ethics approval and consent to participate}

All experiments were approved by the local ethics committee of the University of Pecs, Hungary.

\section{Patient consent for publication}

Not applicable.

\section{Competing interests}

The authors declare that they have no competing interests.

\section{References}

1. Clarke HC: History of endoscopic and laparoscopic surgery. World J Surg 25: 967-968, 2001.

2. Sammour T, Mittal A, Loveday BP, Kahokehr A, Phillips AR, Windsor JA and Hill AG: Systematic review of oxidative stress associated with pneumoperitoneum. Br J Surg 96: 836-850, 2009.

3. Liu KX, Li YS, Huang WQ, Chen SQ, Wang ZX, Liu JX and Xia Z: Immediate postconditioning during reperfusion attenuates intestinal injury. Intensive Care Med 35: 933-942, 2009.

4. Polat C, Yilmaz S, Serteser M, Koken T, Kahraman A and Dilek ON: The effect of different intraabdominal pressures on lipid peroxidation and protein oxidation status during laparoscopic cholecystectomy. Surg Endosc 17: 1719-1722, 2003.

5. Ates E, Yilmaz S, Ihtiyar E, Yasar B and Karahuseyinoglu E: Preconditioning-like amelioration of erythropoietin against laparoscopy-induced oxidative injury. Surg Endosc 20: 815-819, 2006.

6. Hatipoglu S, Akbulut S, Hatipoglu F and Abdullayev R: Effect of laparoscopic abdominal surgery on splanchnic circulation: Historical developments. World J Gastroenterol 20: 18165-18176, 2014.

7. Veres TG, Petrovics L, Sárvári K, Vereczkei A, Jancsó G Farkas KB and Takács I: The effect of laparoscopic pre- and postconditioning on pneumoperitoneum induced injury of peritoneum. Clin Hemorheol Microcirc, May 27, 2019 (Epub ahead of print).

8. Loubele ST, ten Cate H and Spronk HM: Anticoagulant therapy in critical organ ischaemia/reperfusion injury. Thromb Haemost 104: 136-142, 2010.

9. Lipton P: Ischemic cell death in brain neurons. Physiol Rev 79: 1431-1568, 1999.

10. Oksuz H, Bulbuloglu E, Senoglu N, Ciralik H, Yuzbasioglu MF, Kilinc M, Dogan Z, Goksu M, Yildiz H, Ozkan OV and Atli Y: Re-protective effects of pre- and post-laparoscopy conditioning, zinc, pentoxifylline, and $\mathrm{N}$-acetylcysteine in an animal model of laparoscopy-induced ischemia/reperfusion injury of the kidney. Ren Fail 31: 297-302, 2009.

11. Yilmaz S, Ates E, Polat C, Koken T, Tokyol C, Akbulut G and Gokce O: Ischemic preconditioning decreases laparoscopy-induced oxidative stress in small intestine. Hepatogastroenterology 50: 979-982, 2003.

12. Yilmaz S, Koken T, Tokyol C, Kahraman A, Akbulut G, Serteser M, Polat C, Gokce C and Gokce O: Can preconditioning reduce laparoscopy-induced tissue injury? Surg Endosc 17: 819-824, 2003.

13. Zhao ZQ, Corvera JS, Halkos ME, Kerendi F, Wang NP, Guyton RA and Vinten-Johansen J: Inhibition of myocardial injury by ischemic postconditioning during reperfusion: Comparison with ischemic preconditioning. Am J Physiol Heart Circ Physiol 285: H579-H588, 2003.

14. Jávor S, Shanava K, Hocsák E, Kürthy M, Lantos J, Borsiczky B, Takács I, Horváth S, Balatonyi B,Ferencz S, et al: Preconditioning is a method that may reduce the negative side-effect of pneumoperitoneum. Interv Med Appl Sci 2: 115-120, 2010.

15. Placer ZA, Cushman LL and Johnson BC: Estimation of product of lipid peroxidation (malonyl dialdehyde) in biochemical systems. Anal Biochem 16: 359-364, 1966.

16. Sedlak J and Lindsay RH: Estimation of total, protein-bound, and nonprotein sulfhydryl groups in tissue with Ellman's reagent. Anal Biochem 25: 192-205, 1968.

17. Misra HP and Fridovich I: The role of superoxide anion in the autoxidation of epinephrine and a simple assay for superoxide dismutase. J Biol Chem 247: 3170-3175, 1972.

18. Ott DE: The peritoneum and the pneumoperitoneum: A review to improve clinical outcome. Gynecol Surg 1: 101-106, 2004.

19. Lee JY and Choi SH: Evaluation of total oxidant and antioxidant status in dogs under different $\mathrm{CO} 2$ pneumoperitoneum conditions. Acta Vet Scand 57: 23, 2015.

20. Ypsilantis P, Lambropoulou M, Tentes I, Chryssidou M, Georgantas $\mathrm{T}$ and Simopoulos C: Room air versus carbon dioxide pneumoperitoneum: Effects on oxidative state, apoptosis and histology of splanchnic organs. Surg Endosc 30: 1388-1395, 2016.

21. Thuret R, Saint Yves T, Tillou X, Chatauret N, Thuillier R, Barrou B and Billault C: Ischemic pre- and post-conditioning: Current clinical applications. Prog Urol 24 (Suppl 1): S56-S61, 2014. 
22. Trunzo JA, McGee MF, Cavazzola LT, Schomisch S, Nikfarjam M, Bailey J, Mishra T, Poulose BK, Lee YJ, Ponsky JL and Marks JM: Peritoneal inflammatory response of natural orifice translumenal endoscopic surgery (NOTES) versus laparoscopy with carbon dioxide and air pneumoperitoneum. Surg Endosc 24: 1727-1736, 2010.

23. Bingener J, Krishnegowda NK and Michalek JE: Immunologic parameters during NOTES compared with laparoscopy in a randomized blinded porcine trial. Surg Endosc 23: 178-181, 2009.

24. Berguer R, Cornelius T and Dalton M: The optimum pneumoperitoneum pressure for laparoscopic surgery in the rat model. A detailed cardiorespiratory study. Surg Endosc 11: 915-918, 1997.

25. Al-Saeedi M, Nickkholgh A, Schultze D, Flechtenmacher C, Zorn M, Liang R, Gutt CN and Schemmer P: Glycine protects the liver from reperfusion injury following pneumoperitoneum. Eur Surg Res 59: 91-99, 2018.
26. Mateos R, Lecumberri E, Ramos S, Goya L and Bravo L: Determination of malondialdehyde (MDA) by high-performance liquid chromatography in serum and liver as a biomarker for oxidative stress. Application to a rat model for hypercholesterolemia and evaluation of the effect of diets rich in phenolic antioxidants from fruits. J Chromatogr B Analyt Technol Biomed Life Sci 827: 76-82, 2005.

27. Kolagal V, Karanam SA, Dharmavarapu PK, D'Souza R Upadhya S, Kumar V, Kedage V, Muttigi MS, Shetty JK and Prakash M: Determination of oxidative stress markers and their importance in early diagnosis of uremia-related complications. Indian J Nephrol 19: 8-12, 2009.

28. Sack M: Tumor necrosis factor-alpha in cardiovascular biology and the potential role for anti-tumor necrosis factor-alpha therapy in heart disease. Pharmacol Ther 94: 123-135, 2002. 